\title{
Distance teaching and learning in photonics: a 10-year experiment
}

Jürgen Jahns, André Edelmann, Stefan Helfert, Stephanie Supp

Jürgen Jahns, André Edelmann, Stefan Helfert, Stephanie Supp, "Distance teaching and learning in photonics: a 10-year experiment," Proc. SPIE 9793, Education and Training in Optics and Photonics: ETOP 2015, 97931Q (8 October 2015); doi: 10.1117/12.2223132

SPIE Event: Education and Training in Optics and Photonics: ETOP 2015, 2015, Bordeaux, France 


\title{
Distance teaching and learning in photonics - a 10-year experiment
}

\author{
Jürgen Jahns ${ }^{1}$, André Edelmann, Stefan Helfert, Stephanie Supp \\ FernUniversität in Hagen, LG Mikro- und Nanophotonik \\ Universitätsstr. 27/PRG, 58097 Hagen, Germany
}

\begin{abstract}
For 40 years, the FernUniversität in Hagen has been devoted strictly to distance teaching. Ten years ago, an MSc program in Electrical Engineering was started, consisting of different directions of emphasis. One of them is a full 3-4 semester program on Photonics. Here, we report about the concept, the tools, the status and the experiences during recent years with this program.
\end{abstract}

Keywords: optics, photonics, distance learning, e-learning, blended learning, mobile learning

\section{INTRODUCTION}

Photonics is considered as one of the key technologies for the 21st century. With its broad range of applications and economic significance, it has been identified as a key enabling technology by various renowned papers on national and international research policy. To master the challenge of economic change requires first of all adequate high-level education, at high schools and universities. The rapid changes in the area of new technologies makes in mandatory, in addition, to provide suitable paths in continuing education and lifelong learning for the existing workforce. Lifelong learning is one of the biggest political and societal challenges in advanced economies in order to make use of human resources. The process of lifelong learning requires many different paths and measures, one of them being distance teaching at the university level to provide competent education.

The FernUniversität in Hagen (fern, German word for "distant") is devoted to distance learning since it was founded in 1975. It is the only public university for distance learning in the German-speaking countries and provides programs and degrees equivalent to any other German university ${ }^{1}$.

Since 2004, a MSc program in Electrical Engineering and Information Technology is being offered. This is a 3-4 semester program which allows students to select from four (optional: five) "directions of emphasis" so that they can get knowledge and qualification in a specific area. These directions include Communication Networks, Information Technology, Mechatronics, and Photonics. Like the other directions, too, the Photonics program consists of four modules for 7-semester Bachelors (and five modules for 6-semester Bacholors). Each module consists of a two-part course, a lab course and a seminar with a final examation (Fig. 1).

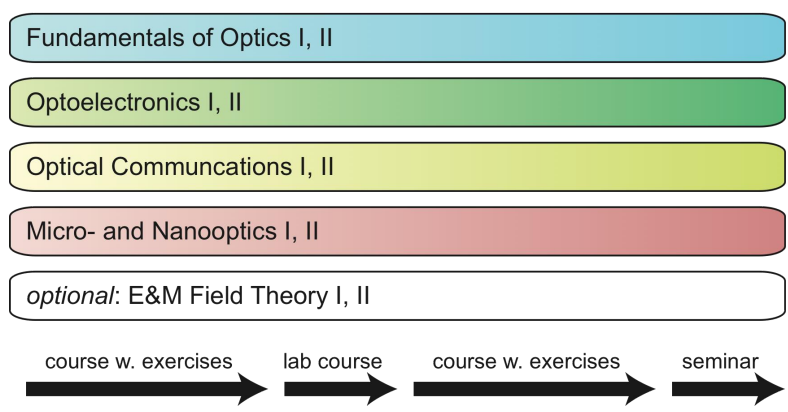

Figure 1. Structure of the Photonics program.

Various tools are used to provide the teaching materials and give students the chance for an optimum degree of flexibility in their time schedule. This includes written documents, internet and multimedia concepts.

1 juergen.jahns@fernuni-hagen.de; phone +49 2331 987-340; fernuni-hagen.de/MNP

Education and Training in Optics and Photonics: ETOP 2015, edited by Eric Cormier, Laurent Sarger Proc. of SPIE Vol. 9793, 97931Q · C 2015 SPIE, IEEE, OSA, ICO · doi: 10.1117/12.2223132 


\section{WRITTEN COURSE MATERIAL}

At the fundemant of the learning process, there are written courses. The courses provide the knowledge that allows students to learn about those areas which are necessary to understand the fundamentals and to qualify for the requirements in their jobs. A few examples are shown in Fig. 2. Courses are provided on a digital platform and can be downloaded by students as pdf-documents.

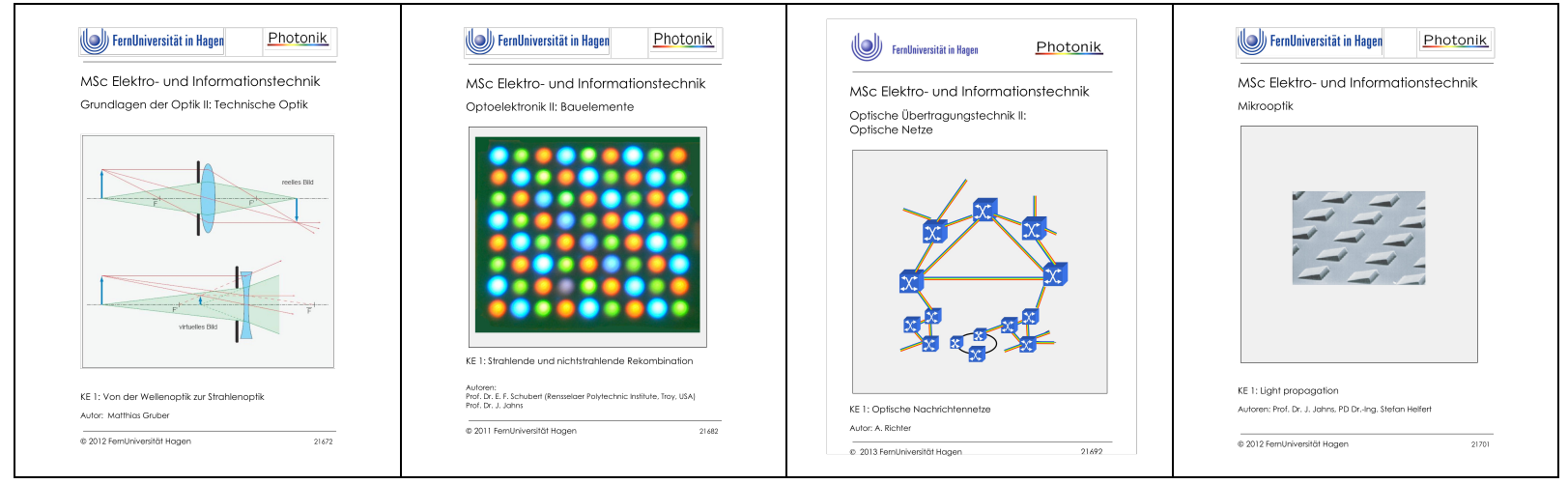

Figure 2. Examples of written courses in the Photonics program.

The course chapters are elaborate texts covering the relevant aspects of a certain topic. They include numerous examples and a list of questions at the end for self-evaluation. After studying a specific chapter, students have to work on exercises to deepen the acquired knowledge. Exercices and corrected exercises are exchanged between student and course tutor by email. However, other suitable tools like, e.g., Moodle and Adobe Connect may also be used and will be discussed below.

Closely combined with the written texts are lab courses, to give students a hands-on experience and a seminar, to make students familiar with original scientific literature.

\section{LAB COURSES}

Even in the age of distance education (or: particularly so), it is essential that students also get practical training (Fig.3). In our program, students have to work on lab exercises in each module. The lab courses are offered in a time-concentrated manner, to allow for a focused procedure. Preparing for a lab course is carried out online by reading a manual and by answering questions and by solving small problems related to the lab course.

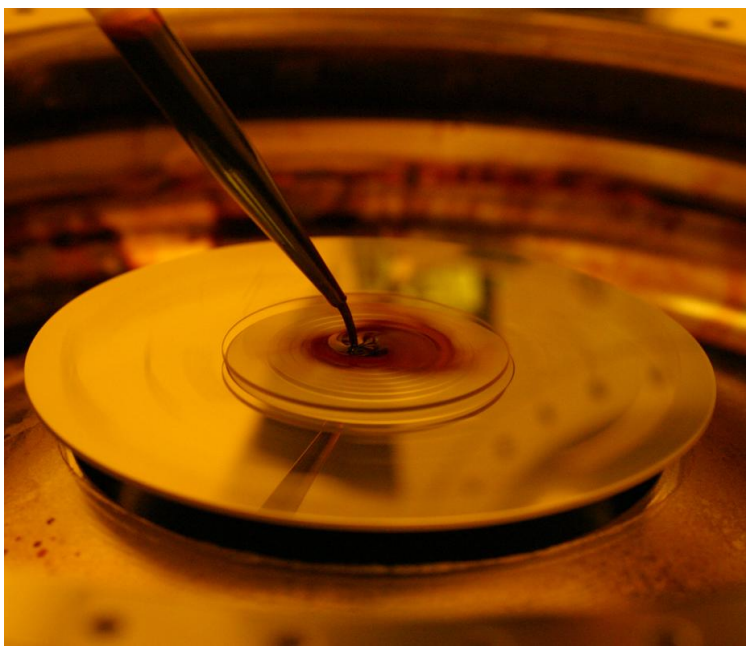

Figure 3. Lab course on microoptics: spinning of photoresist onto a substrate. 


\section{SEMINAR}

The purpose of the seminar is to get students acquainted with original scientific literature. For this, they get an assignment which consists of reading a particular article from the scientific literature and by reporting about it in a 20 minute oral presentation (Fig. 4). Here, the aim is not only to present the contents of the paper, but also to put them in perspective with the learned materials. Furthermore, students are asked to give a critical evalution of the claims and the results described in the article. Preparation for the seminar procedes along a well-defined time schedule by email in order to guide students through the process of understanding and presenting.
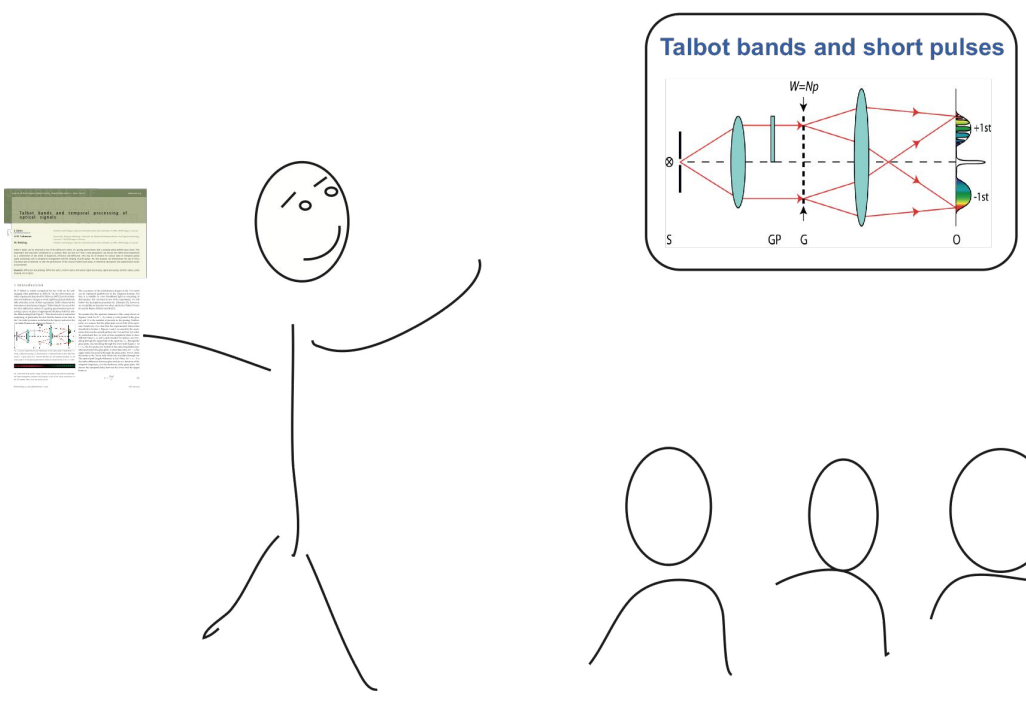

Figure 4. Seminar presentation and discussion.

\section{TOOLS FOR ONLINE-TEACHING AND E-LEARNING}

Some aspects of distance teaching are practically the same as at a "conventional" university. E-learning, however, requires additional measures in order to offer students optimum flexibility and support. This can be achieved by the use of internet-based and multimedia tools (known as "blended learning"). Some of them will be presented in the following.

\subsection{LEARNING CARDS}

The use of "Learning Cards" (or "Virtual Flashcards") means that students can self-evaluate their knowledge by a "question-and-answer" game. The tool was developed by the Chair of Instructional Technology and Media at the FernUniversität in Hagen"2.

This interactive tool consists of virtual index cards as a glossary or simply for learning the terms. It is provieded by an App which can be downloaded to a mobile device (Android and iOS). The use of a mobile device, i.e., smart phone or tablet computer, allows students to use it anywhere and anytime. The Flashcard application is also available in a regular internet browser; a screenshot is shown below (Fig. 5). 


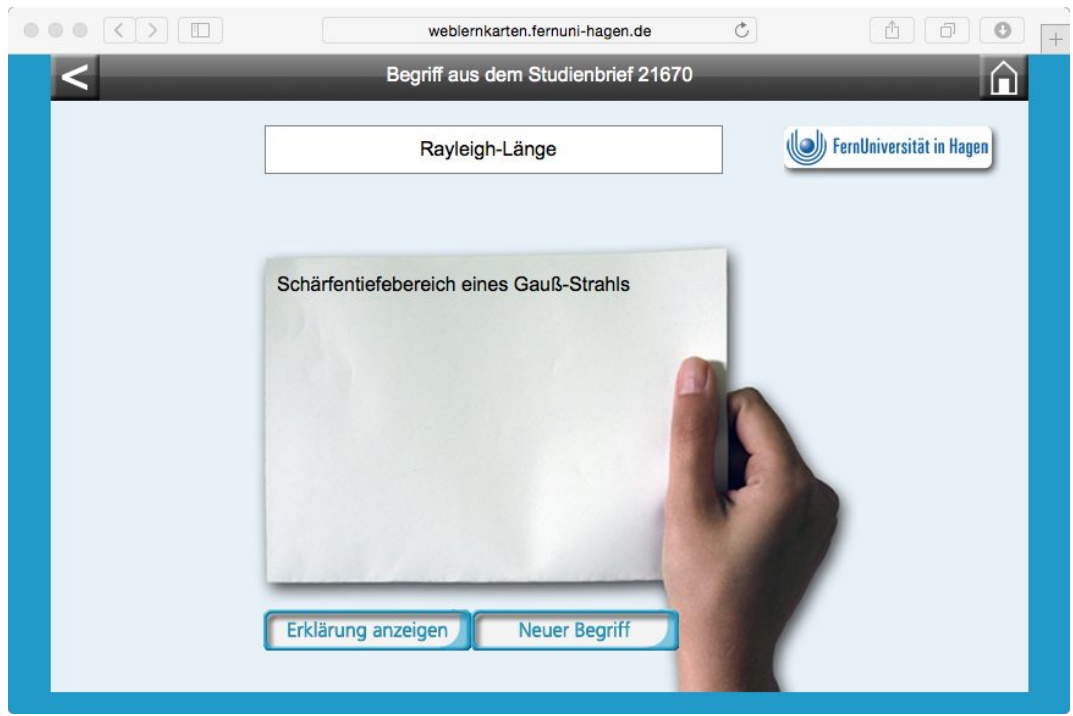

Figure 5. Flashcard (“Lernkarten”) application.

\subsection{E-LEARNING WITH MOODLE}

Moodle was developed by Martin Dougiamas in Australia in 1999. His aim was to create an eLearning-plattform to facilitate communications between tutor and students in contrast to existing plattforms which were just used to hand out teaching and learning contents. Virtual classrooms allow for a direct and online collaboration between students and tutors in separate locations (Fig. 6). By entering a virtual classroom using a personalized account, not only the tutor is given wide ranges of possibilities for addressing the students, but also the students are enabled to take part in the course in an active manner. Here, the tutor can publish texts, links, datafiles, etc. and also create learning activities like forums, quick tests, votings, simple questions which can be answered with 'yes' or 'no', and exercises with determined period for completion or a Wiki. Exercises can be added by the students as a text-datafile or can be imported by the editor implemented into moodle. This degree of freedom in designing this virtual classroom allows an individual active online course environment suitable to learning contents and group size. Students, on the other side, are enabled, for instance, to communicate with other course participants by creating and answering articles in learning activities like creating wiki-articles, glossaries, requests in fora by intergroup development. Moreover communication can be also realized by a chatroom function or publishing Adobe Connect links.

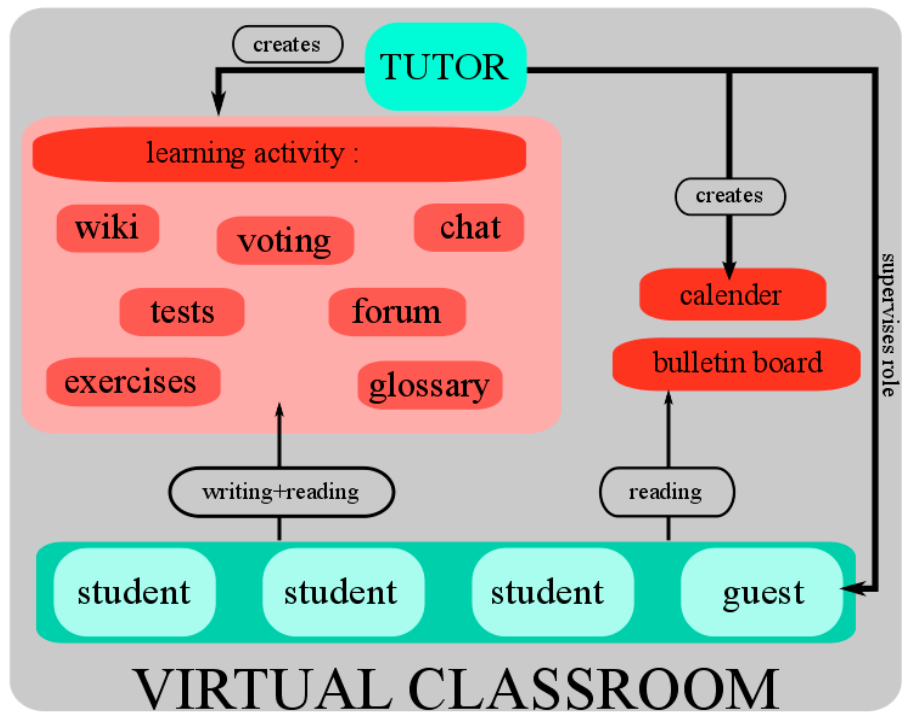

Figure 6. Moodle virtual classroom. 


\subsection{E-LEARNING WITH ADOBE CONNECT}

Another approach to implement virtual classrooms is given by the software Adobe Connect. It enables a collaboration of up to 200 participants at the same time. Various didactic fields are available in the virtual classroom of Adobe Connect e.g., online seminars, lectures, consultation hours and discussion groups. Here different tools for the virtual collaboration can be used e.g., live-presentations, white boards, application sharing. In contrast to the asynchronous environment of Moodle the virtual classroom allows a synchronous audio-visual communication between the participants. Figure 7 shows a typical setting of a virtual consultation hour. On the left one can find the video channels and on the right the document under discussion. Both participants have access to the document and can e.g., use markers to specify the area of interest in the document (see green marker in Fig. 7). Furthermore the discussions in the virtual classroom can be recorded for later considerations or documentations. Due to the audio-visual communication the virtual consultation hour is quite similar to a „real“ consultation hour and in particular appropriated for discussion of complex issues.

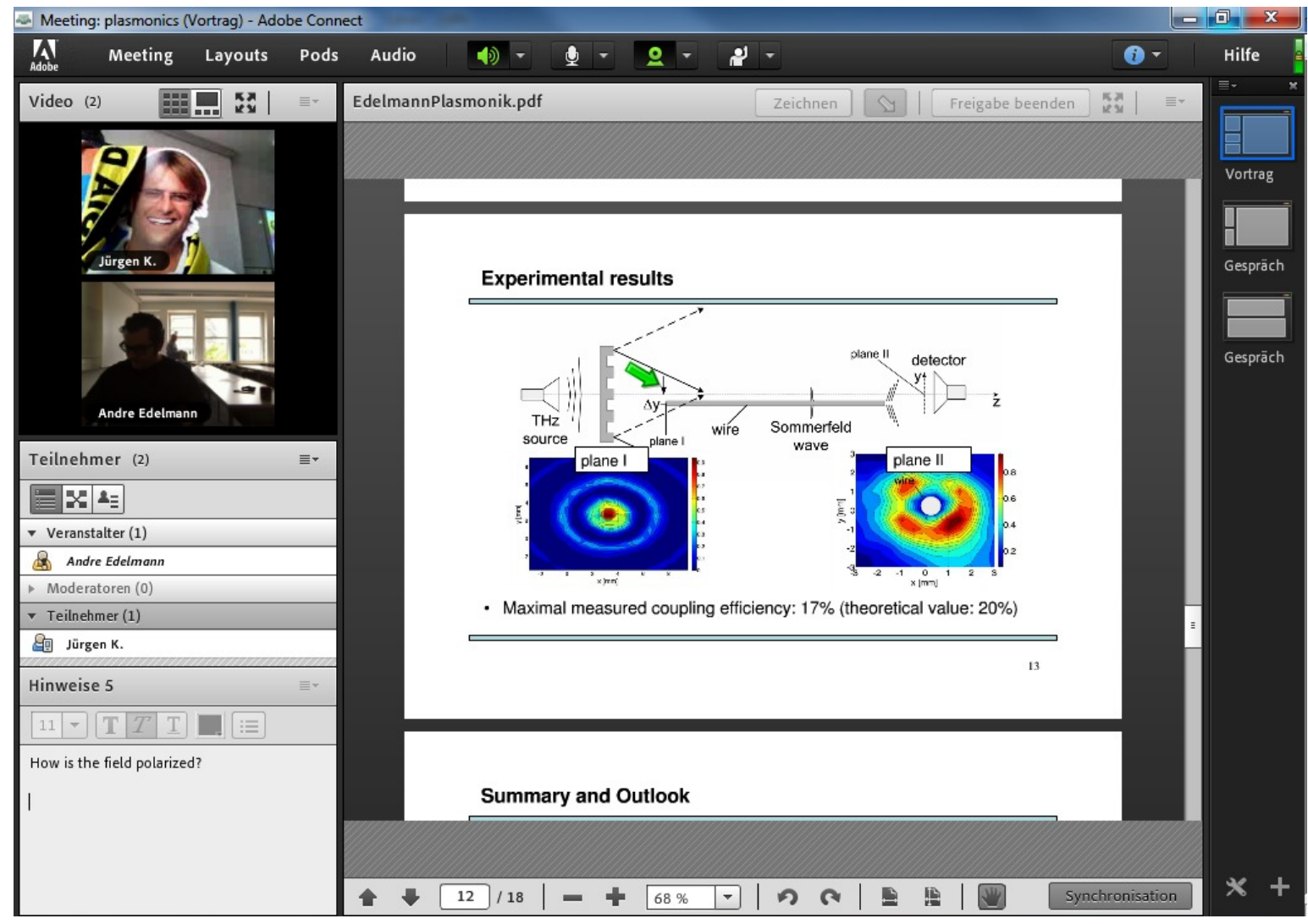

Figure 7. Adobe Connect virtual classroom.

\subsection{LIVE-STREAMING EXERCISES WITH ADOBE CONNECT}

In the "distance teaching," students generally live and work far away from the university. Therefore, weekly "face-to-face meetings" to discuss, e.g., the homework assignments are not possible. As an alternative, online exercises are provided. These online exercises can be processed by email, see above, but they can also be carried out with Adobe Connect. The connection steps are identical to what was just described above. Unlike the conversation in the previous example, a more directional transmission from the lecturer to the various students takes place (i.e., more like a broadcast). However, since all Adobe tools are available, interaction is possible. For example, the students can ask questions during the lecture. During online exercises, the main focus lies in showing solutions of certain tasks step by step, rather than presenting complete expressions. As in "real" classrooms, the equations may therefore be written, as here, for example, by hand on an electronic whiteboard. In this way, the data are directly transmitted to the students. This is shown in the screenshot from the perspective 
of the student's computer (Fig. 8). In this example the student sees the lecturer writing Maxwell's equations on the whiteboard.

Generally, the screen of the lecturer is transmitted to the student's computer. Hence, (except from a slightly lower resolution) the students may see everything as in an on-site presentation, where a projector would be used. It is also possible to show further material, like simple movies (simple, because of limited bandwidth), to illustrate the results.

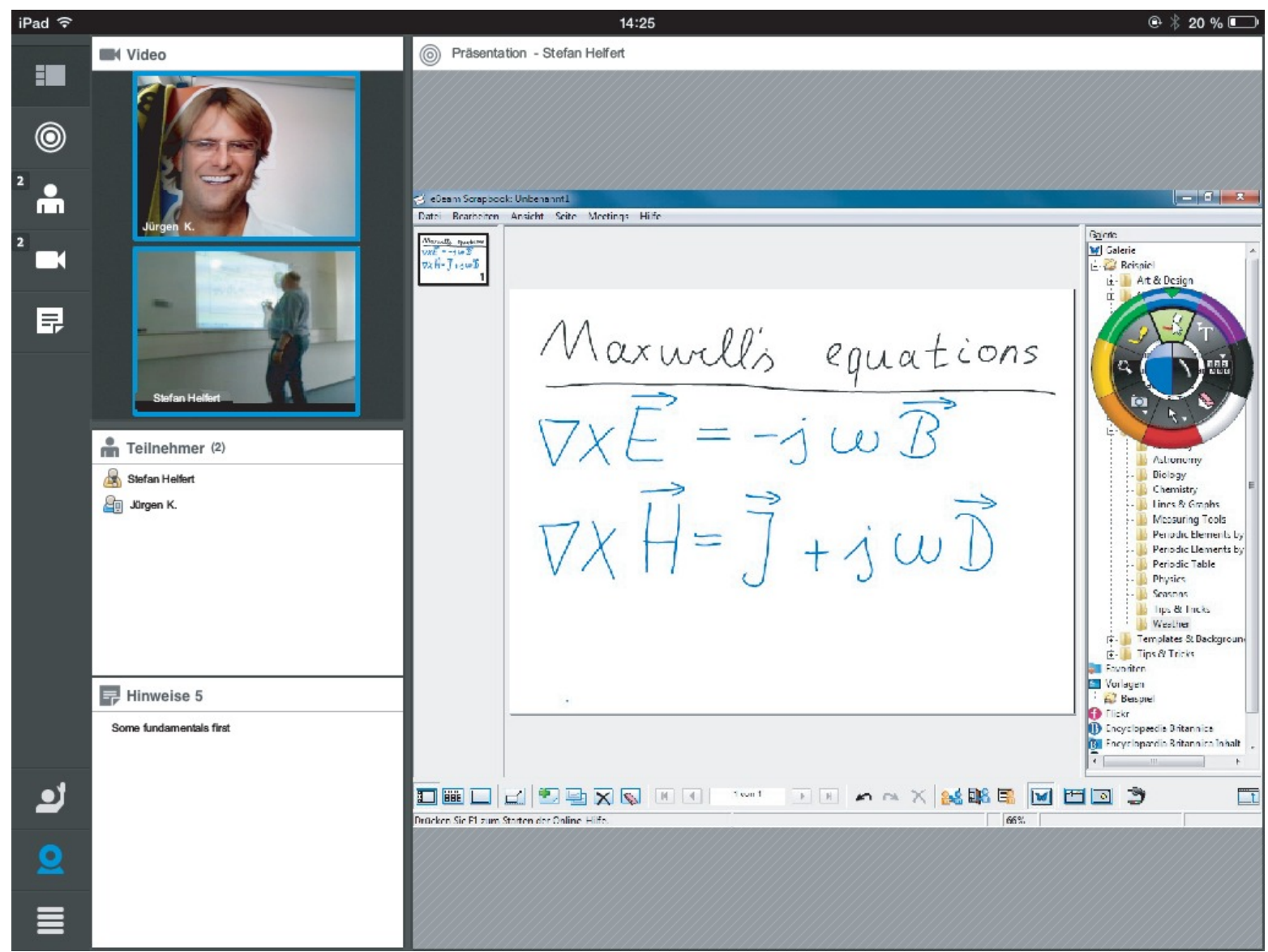

Figure 8. Adobe Connect virtual classroom: student's perspective.

\section{CONCLUSION}

Distance teaching in the natural sciences and in engineering is a challenging task, even more than in the social and cultural sciences, for example. The challenges stem on one side from the difficulty of the subject itself and the formalized language that is used in engineering and physics-related sciences. This causes the need of creating a suitable learning environment that "virtually" eliminates the biggest difficulty for students, which is usually the lack of direct interaction with professors and tutors on the on side and other students on the other side. In an "ideal" scenario, the teaching system is founded on several pillars: it combines classical tools such as written material and practical lab courses with new internet-based tools and multimedia applications, adequately crosslinked to complement and enhance each other ("blended learning").

During the past 10 years, some 200 students were enrolled in the program on Photonics. 50 of them were successful in getting their MSc degree, nearly all of them while working in a full-time job.

It is important to note at the end, that a plethora of support is available for students and teachers from the university with regards to issues such as the didactics of e-learning, technical aspects of internet-based training, and the conception of distance learning/teaching in general. 


\section{REFERENCES}

1. http://www.fernuni-hagen.de

2. http://ifbm.fernuni-hagen.de/lehrgebiete/mediendidaktik/tools and more/elearning

3. M. Turoff, C. Howard, R. Discenza, Technology's Role in Distance Education, Ch. 1.2 in: M.-A. Sicilia, E. G. Barriocanal, On the Convergence of Formal Ontologies and Standardized E-Learning, IGI Global (2008).

\section{ACKNOWLEDGMENTS}

We would like thank for the support of Veronika Kral, Thomas Seiler and Boguslaw Wdowiak (Lehrgebiet Mikro- und Nanophotonik), Werner Schubert (Lehrgebiet Kommunikationsnetze), the Lehrgebiet Mediendidaktik (Prof. Theo Bastiaens) and Bernhard Vogeler (Zentrum für Medien und IT). 